\title{
Reactive Centers of Curcumin and the Possible Role of Metal Complexes of Curcumin as Antioxidants
}

\author{
Priya. R. S ${ }^{1}$, Balachandran. $S^{2}$, Joseph. Daisy ${ }^{3, *}$, Mohanan. P. $\mathbf{~}^{1}$ \\ ${ }^{1}$ Department of Applied Chemistry, Cochin University of Science and Technology, India \\ ${ }^{2}$ Department of Chemistry, Mahatma Gandhi College, India \\ ${ }^{3}$ Nuclear Physics Division, Bhaba Atomic Research Center, India
}

Copyright (C) 2015 Horizon Research Publishing All rights reserved.

\begin{abstract}
Curcumin is known as a blood purifier in Ayurveda which has been recently ascribed to its chelating ability with metal, hence reducing the deposition of metal in the body. Curcumin can exhibit keto-enol tautomerism and in the synthesized 1:1 metal complexes, the enolate ion chelate to the metal. The antioxidant activity of the synthesized metal complexes of curcumin was slightly less than the parent curcumin-I. Curcumin in the complexed state retains its antioxidant behavior, consequently establishing importance of phenolic group in deciding its antioxidant activity. The study reveals that the flexibility at the diketo moiety is not a requisite for the radical formation and sufficient scavenging of DPPH occur by phenoxide ion formation.
\end{abstract}

Keywords Curcumin, Metal Complex, DPPH, Antioxidant

\section{Introduction}

Turmeric, the rhizome from the plant Curcuma longa has been in use for centuries for the treatment of various ailments in Indian traditional system of healing Ayurveda, which mean the science of long life [1]. Studies in the last few decades revealed that, curcumin, the diferolyl methane is mainly responsible for the biological activities of turmeric $[2,3,4,5]$. The hydroxyl group attached to the two aromatic rings and the $\beta$-diketo moiety connected to the ring through conjugated system in curcumin are suggested to be the active centres for its activity. The diketone have a good ability to interact with a great number of metal ions and form a stable complex by different mode of chelation [6,7]. The metal complexes of curcumin with copper, iron and some other metals are reported which involve the chelation via diketo moiety $[8,9,10]$. The contribution of metal in neurodegenerative disorder such as Alzheimer disease (AD), mitochondrial disorder, Wilson's disease and Parkinson's disease were recently reported [11] and a number of clinical trials were performed to test the ability of natural antioxidant including curcumin [12] to slow down the progression of $\mathrm{AD}$. In animal studies, curcumin was found to remove heavy metal accumulation in rat brain thus preventing lipid peroxidation induced by metal [6]. Curcumin exhibit unique charge and bonding characteristic [13] that facilitate penetration into the blood brain barrier superior to other known nonsteroidal anti-inflammatory drug (NSAID)[14] and Congo red[15].The effectiveness of curcumin against oxidative stress is well established and is directly related to the decrease in plaque formation in brain cell [15] the primary factor responsible for $\mathrm{AD}$.

The free radical reaction centers of curcumin has been suggested as its two phenolic groups, enol form of the diketone moiety and extended conjugated structure. The major contributing center is still a controversy. The mechanistic aspects of curcumin antioxidant activity have been more recently investigated at length, and the recent studies $[16,17,18,19,20,21]$ seem to suggest the importance of phenolic - $\mathrm{OH}$ as was earlier surmised by Barclay et al., 2000 and Venkatesan and Rao, 2000 [22,23]. A possible role for $\beta$-diketone moiety was suggested by Sugiyama et al., 1996 [24] based on their observations using dimethyltetrahydrocurcumin and further advocated by the work of Jovanovic et al., 1999 [25].

The antioxidant activity of the ligand curcumin and its complexes are compared using DPPH, an all radical quencher. The objective of the study was to relate the role of enol form of curcumin which is absent in the metal complexes in deciding the antioxidant activity as when compared to the phenolic centers of curcumin.

\section{Materials and Methods}

\subsection{Materials}

The curcumin-I for the synthesis of metal complex was isolated by column chromatography of the commercial sample of curcumin purchased from Kancor Ingredients Ltd, 
Angamaly, Kerala. The DPPH was purchased from Sigma-Aldrich Co, St. Louis, USA. The metal salts, Cupric chloride $\left[\mathrm{CuCl}_{2} .2 \mathrm{H}_{2} \mathrm{O}\right]$, Magnesium chloride $\left[\mathrm{MgCl}_{2} \cdot 6 \mathrm{H}_{2} \mathrm{O}\right]$, Cobalt chloride $\left[\mathrm{CoCl}_{2} \cdot 6 \mathrm{H}_{2} \mathrm{O}\right]$, Manganous chloride $\left[\mathrm{MnCl}_{2}\right.$. $4 \mathrm{H}_{2} \mathrm{O}$ ] were purchased from S.D. Fine Chem. Ltd, Nickel chloride $\left[\mathrm{NiCl}_{2} \cdot 6 \mathrm{H}_{2} \mathrm{O}\right]$ from Universal Laboratories Private Ltd. The analytical grade piperidine from Merck and the solvents were purchased from, S.D. Fine Chem. Ltd.

\subsection{Methods}

${ }^{1} \mathrm{H}$ NMR spectra were recorded in a Bruker Advance DRX 300 FT-NMR spectrometer with TMS as the internal standard. CHN analysis was done on an Elementar model Vario EL III CHN analyser. FT-IR spectra were recorded by $\mathrm{KBr}$ pellet method with JASCO-8000 Fourier Transformer Infrared Spectrophotometer in the range $400-4000 \mathrm{~cm}^{-1}$. Thermo electron Nicolet Evolution 300 UV-vis spectrophotometer was used to record the electronic spectra of complex in DMSO and for the study of radical scavenging activity by DPPH method. EDXRF set up, consisting of Radioisotope $\mathrm{Cd}^{109}$ induced X-ray fluorescence spectrometer and $\mathrm{Si}(\mathrm{Li})$ detector of resolution $170 \mathrm{eV}$ at $5.9 \mathrm{KeV} \mathrm{Mn}$ $\mathrm{X}$-rays was used to estimate the metal content in the complex. TG-DTG analysis studies of the complexes were performed on Perkin Elmer Pyris Diamond 6 Thermo gravimetric Analyzer in nitrogen atmosphere in the temperature range of $40-600^{\circ} \mathrm{C}$ and heating rate of $10^{\circ} \mathrm{C}$ per minute. Powdered samples of about $3 \mathrm{mg}$ were sealed in standard platinum pans. The instrument was calibrated using indium and tin as standards. Sample residual weight (TG curves) and its derivative (DTG curves) versus temperature were automatically generated by Pyris software. The molar conductivities of the curcumin complexes in dimethylsulphoxide (DMSO) solutions $\left(10^{-3} \mathrm{M}\right)$ were measured at room temperature using direct reading conductivity meter (Systronic conductivity bridge type 305).

\subsection{Separation of curcumin- I.}

Commercial curcumin which is a mixture of three closely related components curcumin-I (77\%), curcumin-II (18\%) and curcumin-III (3\%) was subjected to silica gel (60-120 mesh) column chromatography, initially run by $\mathrm{CHCl}_{3}$ till the oily layer start to elute. As the three color bands, yellow, dark yellowish orange and brown begin to separate; the polarity of the eluent was increased by using chloroform-methanol mixture in the ratio 9:1 [26]. Each 20 $\mathrm{mL}$ fraction was collected separately and analysed by TLC in Merck silica gel $\mathrm{F}_{254}$ plates using chloroform-methanol (9:1) as mobile phase. The spots were visualized in UV chamber at $254 \mathrm{~nm}$. The fractions with single spot were combined and solvents were removed to give pure components. The first fraction eluted was curcumin-I and identified by NMR provided as Supplementary material (S1) and MS.Yield 78\% (m.p. $\left.186^{\circ} \mathrm{C}\right), \mathrm{UV} \lambda_{\max }=434 \mathrm{~nm}(\mathrm{DMSO}), \mathrm{IR}(\mathrm{KBr}) \vee\left(\mathrm{cm}^{-1}\right)$ : $3494(\mathrm{O}-\mathrm{H}), 1623(\mathrm{C}=\mathrm{O}), 1500(\mathrm{C}=\mathrm{C}), 1271$ (C-O phenol), 1029 (C-O methoxy). ${ }^{1}$ H N.M.R. (300MHz, DMSO-D 6 ) $\delta$ $3.9\left(\mathrm{~s}, 6 \mathrm{H},-\mathrm{OCH}_{3}\right), 6.065(\mathrm{~s}, 1 \mathrm{H}, \mathrm{enol}), 6.73(\mathrm{~d}, 2 \mathrm{H}, \mathrm{J}=16 \mathrm{~Hz})$, 6.81-7.32 (6H,aromatic), $\quad 7.5 \quad(\mathrm{~d}, 2 \mathrm{H}, \mathrm{J}=16 \mathrm{~Hz}), \quad 9.66$ (s,2H,-OH phenol), MS m/z: 367(M-1).

\subsection{Preparation of metal complexes of curcumin-I (I-5).}

The methanol solution of curcumin-I $(0.27 \mathrm{mmol})$ and the metal salt $(0.27 \mathrm{mmol})$ were prepared separately and to the curcumin solution catalytic amount of piperidine was added followed by metal salt solution with constant stirring [27]. The stirring was continued for $4 \mathrm{~h}$. The metal complex precipitated (Scheme-1), was filtered and washed several time with cold methanol to remove the residual reactant and dried in vacuum.

Scheme-1
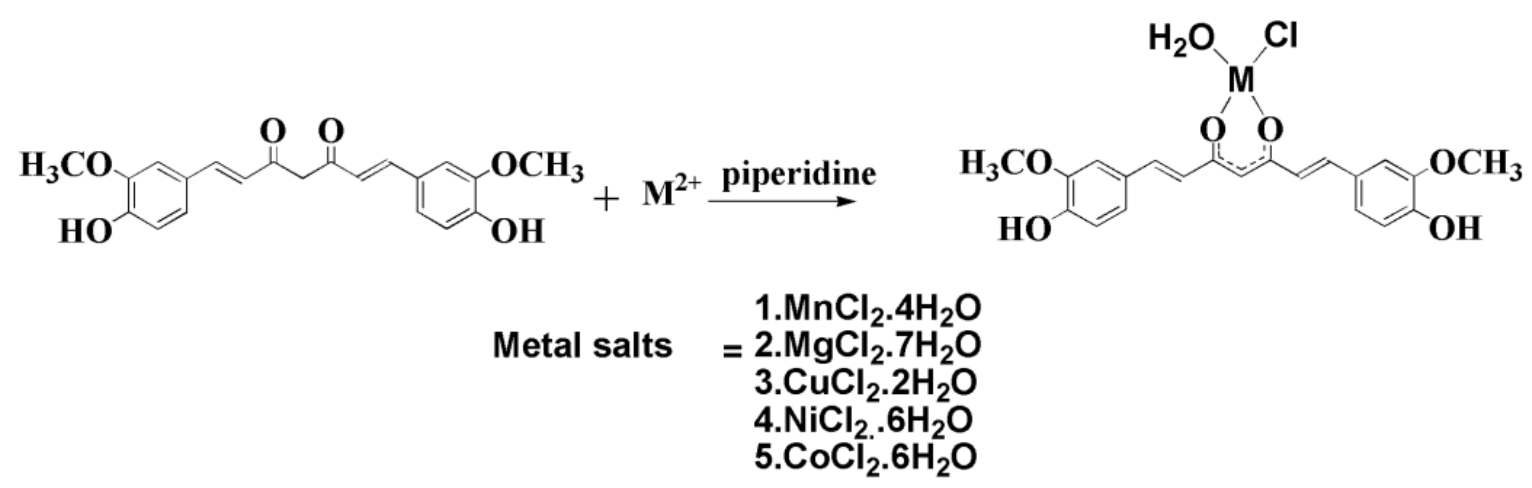

Synthesis of metal complex of Curcumin-I

Curcumin-I, Piperidine, Methanol, stirring at room temperature for $4 \mathrm{hrs}$. 
S1 NMR of curcumin-I

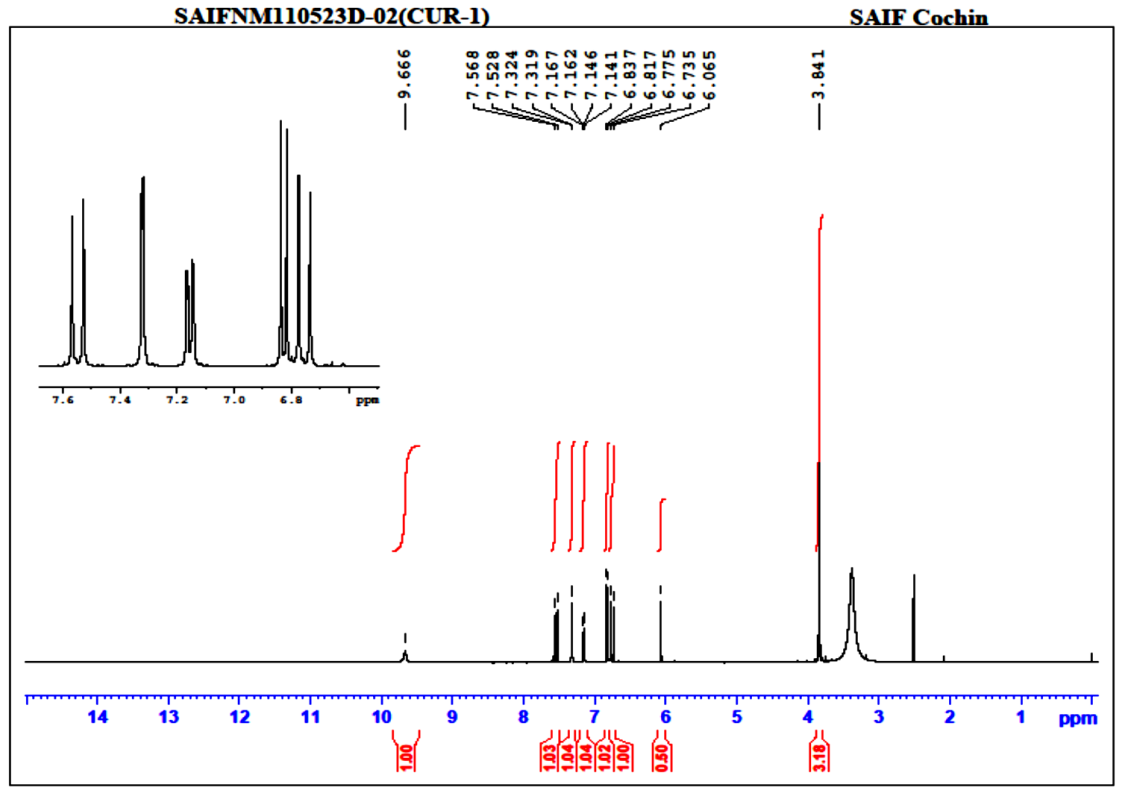

\subsubsection{Mn-Curcumin complex (1)}

Yield: $63 \%$, UV $\lambda_{\max }=442 \mathrm{~nm},(\mathrm{DMSO})$. IR $(\mathrm{KBr}) v$ $\left(\mathrm{cm}^{-1}\right): 3433(\mathrm{O}-\mathrm{H}), 1579(\mathrm{C}=\mathrm{O}), 1500(\mathrm{C}=\mathrm{C}), 1287(\mathrm{C}-\mathrm{O}$ phenol), 1015 (C-O methoxy). Anal. Calc for $\mathrm{C}_{21} \mathrm{H}_{21} \mathrm{ClMnO}_{7}$ : C, 53.01; H, 4.45; Mn, 11.55. Found: C, 53.88; H, 4.70; Mn, 11.30 .

\subsubsection{Mg-Curcumin complex (2)}

Yield: $58 \%$, UV $\lambda_{\max }=437 \mathrm{~nm}$, (DMSO). IR (KBr) $v$ $\left(\mathrm{cm}^{-1}\right): 3428(\mathrm{O}-\mathrm{H}), 1598(\mathrm{C}=\mathrm{O}), 1500(\mathrm{C}=\mathrm{C}), 1277(\mathrm{C}-\mathrm{O}$ phenol), 1023 (C-O methoxy). Anal. Calc for $\mathrm{C}_{21} \mathrm{H}_{21} \mathrm{ClMgO}_{7}$ : C, 56.66; H, 4.76; Mg, 5.46. Found: C, 56.76; H, 4.56; Mg, 5.98 .

\subsubsection{Cu-Curcumin complex (3)}

Yield: $52 \%$, UV $\lambda_{\max }=439 \mathrm{~nm}(\mathrm{DMSO})$. IR $(\mathrm{KBr}) \vee\left(\mathrm{cm}^{-1}\right)$ : $3429(\mathrm{O}-\mathrm{H}), 1606(\mathrm{C}=\mathrm{O}), 1500(\mathrm{C}=\mathrm{C}), 1276$ (C-O phenol), 1019 (C-O methoxy). Anal. Calc for $\mathrm{C}_{21} \mathrm{H}_{21} \mathrm{ClCuO}_{7}$ : C, 52.07; $\mathrm{H}, 4.37$; $\mathrm{Cu}, 13.12$. Found: $\mathrm{C}, 52.17 ; \mathrm{H}, 4.25 ; \mathrm{Cu}, 13.18$.

\subsubsection{Ni-Curcumin complex (4)}

Yield: $56 \%$, UV $\lambda_{\max }=443 \mathrm{~nm}$, (DMSO). IR (KBr) $v$ $\left(\mathrm{cm}^{-1}\right): 3422(\mathrm{O}-\mathrm{H}), 1619(\mathrm{C}=\mathrm{O}), 1500(\mathrm{C}=\mathrm{C}), 1270(\mathrm{C}-\mathrm{O}$ phenol), 1031 (C-O methoxy). Anal. Calc for $\mathrm{C}_{21} \mathrm{H}_{21} \mathrm{Cl}_{2} \mathrm{NiO}_{7}$ : C, 52.60; H, 4.41; Ni, 12.24. Found: C, 52.34; H, 4.50; Ni, 12.50 .

\subsubsection{Co-Curcumin complex (5)}

Yield: $59 \%$, UV $\lambda_{\max }=438 \mathrm{~nm}(\mathrm{DMSO})$. IR $(\mathrm{KBr}) \vee\left(\mathrm{cm}^{-1}\right)$ : $3434(\mathrm{O}-\mathrm{H}), 1579(\mathrm{C}=\mathrm{O}), 1500(\mathrm{C}=\mathrm{C}), 1279$ (C-O phenol), 1027 (C-O methoxy). Anal. Calc for $\mathrm{C}_{21} \mathrm{H}_{21} \mathrm{ClCoO}_{7}$ : C, 52.57; H, 4.41 Co, 12.28. Found: C, 52.14; H, 4.73; Co, 12.50

\subsection{Antioxidant Property of Curcumin and its Metal Complexes Using DPPH Free Radical}

The free radical scavenging ability of curcumin and the metal complexes were studied using DPPH assay. Curcumin-I (1 mg mL $\left.{ }^{-1}\right)$ or its metal complex $\left(0.5 \mathrm{mg} \mathrm{mL}^{-1}\right)$ in DMSO in the range of $10-150 \mu \mathrm{L}$ were added to definite volume of DPPH $(0.01 \mathrm{mmol})$ in methanol and made up to a final volume of $3 \mathrm{~mL}$ using methanol as solvent. The scavenging ability of curcumin and its metal complexes were monitored spectrophotometrically in terms of decrease in absorbance at $517 \mathrm{~nm}$ after $20 \mathrm{~min}$. Percentage inhibition was calculated using equation (1).

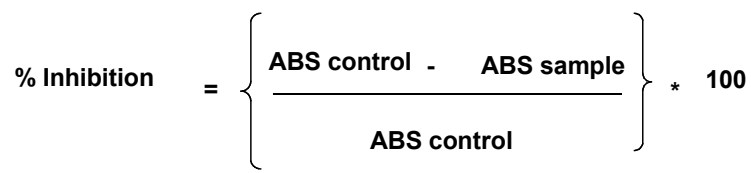

From concentration $(\mu \mathrm{M})$ against absorbance graph, 50\% fall in absorbance of DPPH solution was determined. The above concentration values were used for the determination of $\mathrm{IC}_{50}$ values in $\mu \mathrm{M}$.

\section{Results and Discussion}

The synthesized metal complexes of curcumin have 1:1 metal to ligand ratio as evident by the $\mathrm{CHN}$ and the radioisotope induced EDXRF analysis used to estimate the metal content. The metal to ligand ratio of $1: 1$ was in agreement with previously reported copper and manganese complex of curcumin $[8,10]$. In order to establish the relative importance of phenolic and enolic center to the antioxidant activity of curcumin, the synthesis of only 1:1 complexes were attempted even though 1:2 complexes of curcumin were also reported [8]. This was to retain the number of phenolic group as two, similar to the parent curcumin-1. The UV spectra of curcumin-I exhibited a peak at $434 \mathrm{~nm}$ and in metal complexes (1-5) the absorption maxima was shifted to a region of 437-442 $\mathrm{nm}$ provided as Supplementary 
material (S2) . The complexes (1-5) exhibited a shoulder peak in the range of (450-463 nm) indicating Curcumin $\rightarrow$ Metal $\left(\mathrm{M}^{2+}\right)$ charge transfer transition. The absorption data obtained was in agreement with the data for 1:1 complexes as suggested by Barik et al., 2007 [8]. For 1:2 complex Barik et al showed an absorption in the range of $370 \mathrm{~nm}$. Curcumin exhibits keto-enol tautomerism, the enol form that predominate in basic condition easily gets deprotonated to give enolate ion, which is capable of forming very stable complex with a vast range of metal ion (Fig. 1). In acidic condition the diketone form predominate which can also undergo metal chelation. The strong $\mathrm{C}=\mathrm{O}$ stretching peak observed for curcumin-I at $1623 \mathrm{~cm}^{-1}$ showed a blue shift in metal complex and the value assigned are $1579 \mathrm{~cm}^{-1}, 1598$ $\mathrm{cm}^{-1}, 1606 \mathrm{~cm}^{-1}, 1619 \mathrm{~cm}^{-1}$ and $1579 \mathrm{~cm}^{-1}$ for $\mathrm{Mn}(\mathrm{II})$, $\mathrm{Mg}(\mathrm{II}), \mathrm{Cu}(\mathrm{II}), \mathrm{Ni}(\mathrm{II})$ and $\mathrm{Co}(\mathrm{II})$ complex respectively. The IR data of the synthesized complex provided as Supplementary material (S3) suggest typical chelation mode, (Fig. 1) where the ionic enol form is chelated with metal. This type of chelation is reported for $\mathrm{Cd}(\mathrm{II})$ and $\mathrm{Pb}(\mathrm{II})$ complex of curcumin [6]. In the IR spectra of curcumin and its metal complexes the - $\mathrm{OH}$ band do not show a shift from
$3433 \mathrm{~cm}^{-1}$ hence concluded that the phenolic $-\mathrm{OH}$ is not involved in the complex formation.

S2 UV-visible spectral data of curcumin-I and its metal complexes in DMSO $10^{-5} \mathrm{molL}^{-1}$

\begin{tabular}{|c|c|c|}
\hline Sl .No & Compound & $\lambda$ max, $\mathrm{nm}\left(\mathrm{cm}^{-1}\right)$ \\
\hline & Cur & 434 \\
\hline 1 & Mn-Cur & 442 \\
\hline 2 & Mg-Cur & 437 \\
\hline 3 & Cu-Cur & 439 \\
\hline 4 & Ni-Cur & 443 \\
\hline 5 & Co-Cur & 438 \\
\hline
\end{tabular}

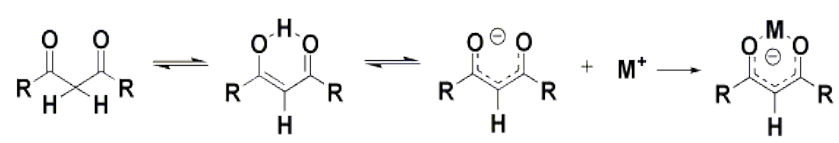

Figure 1. Enolate ion formation of 1,3 diketones in the basic medium

S3 FTIR band's of curcumin-I and its metal complexes and their assignments

\begin{tabular}{|c|c|c|c|c|c|c|}
\hline Sl.No & Compound & $v(\mathrm{O}-\mathrm{H})\left(\mathrm{cm}^{-1}\right)$ & $v(\mathrm{C}=\mathrm{O})\left(\mathrm{cm}^{-1}\right)$ & $v(\mathrm{C}=\mathrm{C})\left(\mathrm{cm}^{-1}\right)$ & $v(\mathrm{C}-\mathrm{O}$ phenol $)\left(\mathrm{cm}^{-1}\right)$ & $v\left(-\mathrm{OCH}_{3}\right)\left(\mathrm{cm}^{-1}\right)$ \\
\hline & Curcumin-I & 3440 & 1628 & 1500 & 1271 & 1029 \\
\hline 1 & Mn-Cur(1) & 3433 & 1579 & 1500 & 1287 & 1015 \\
\hline 2 & Mg-Cur(2) & 3428 & 1598 & 1500 & 1277 & 1023 \\
\hline 3 & Cu-Cur(3) & 3429 & 1606 & 1500 & 1276 & 1019 \\
\hline 4 & Ni-Cur(4) & 3422 & 1619 & 1500 & 1270 & 1031 \\
\hline 5 & Co-Cur(5) & 3434 & 1579 & 1500 & 1279 & 1027 \\
\hline & & & & & & \\
\hline
\end{tabular}




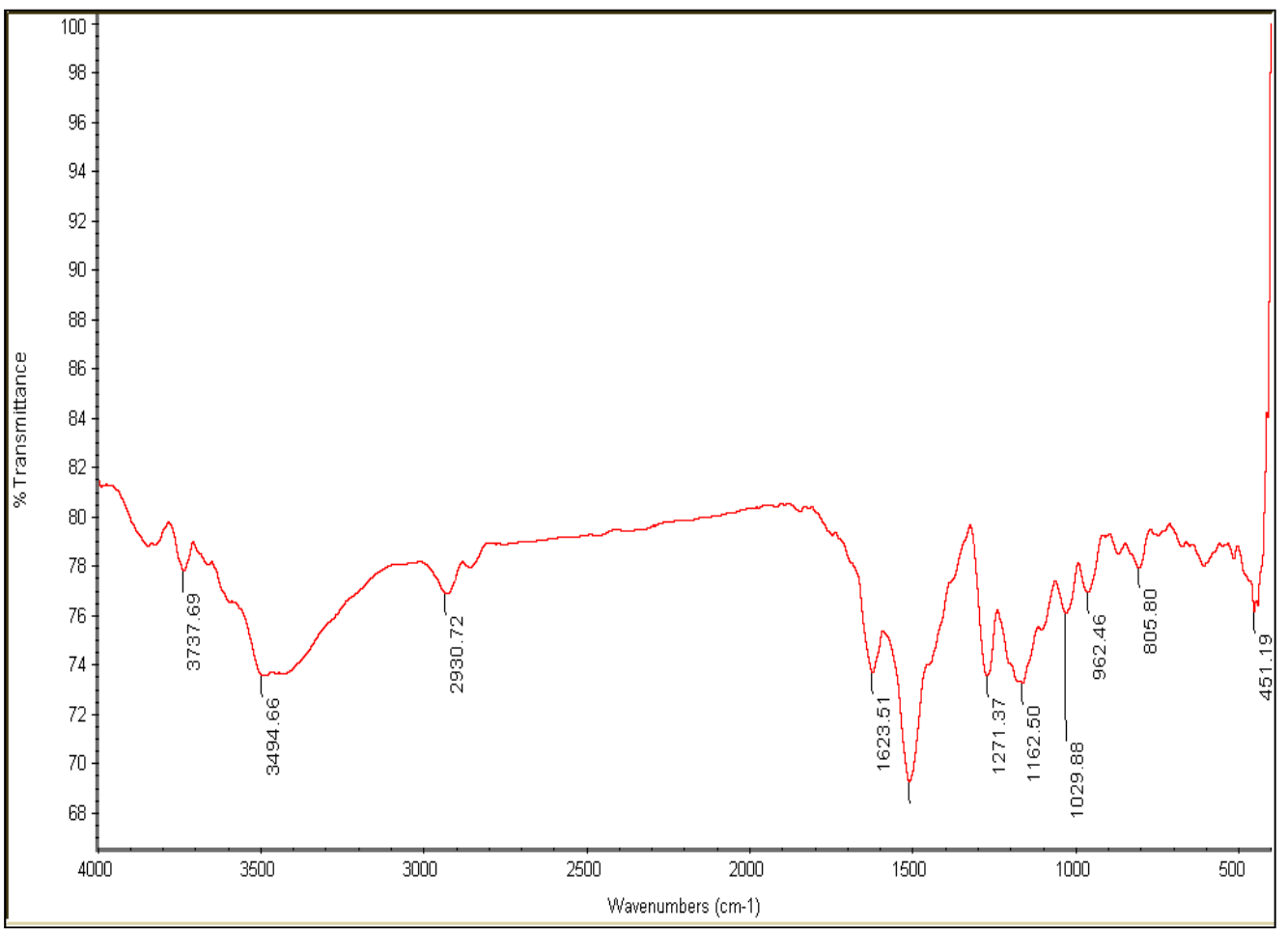

FTIR spectrum of curcumin-I

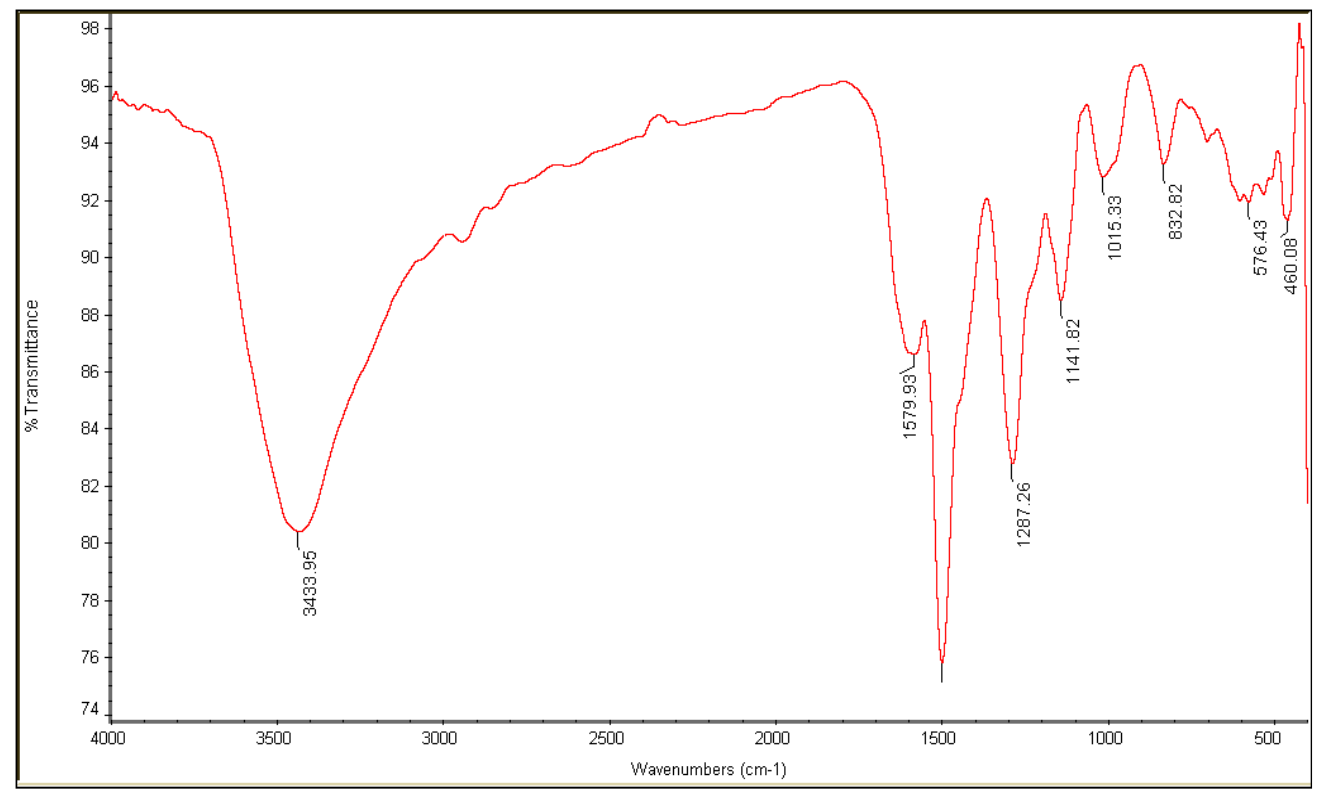

FTIR spectrum of Mn-curcumin complex 


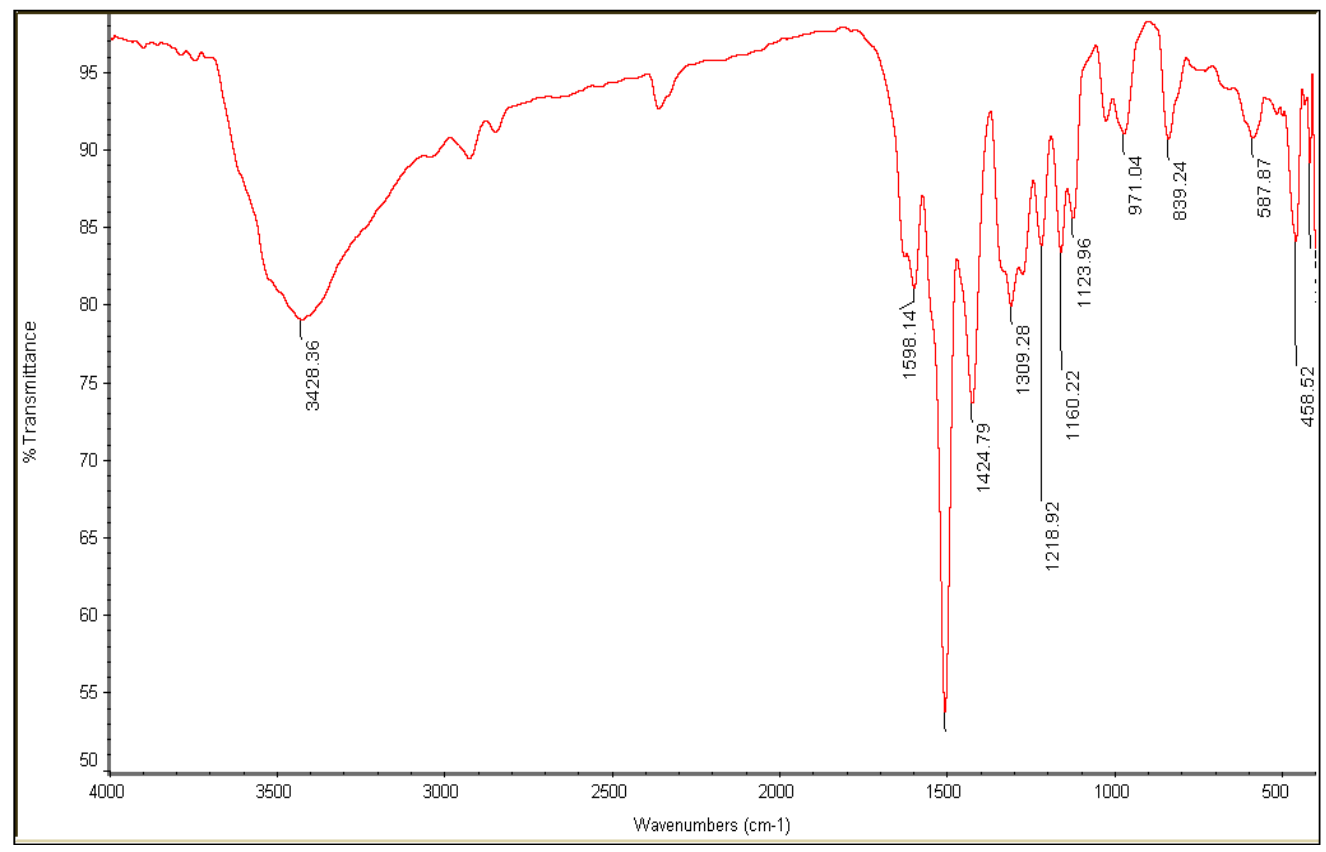

FTIR spectrum of Mg-curcumin complex

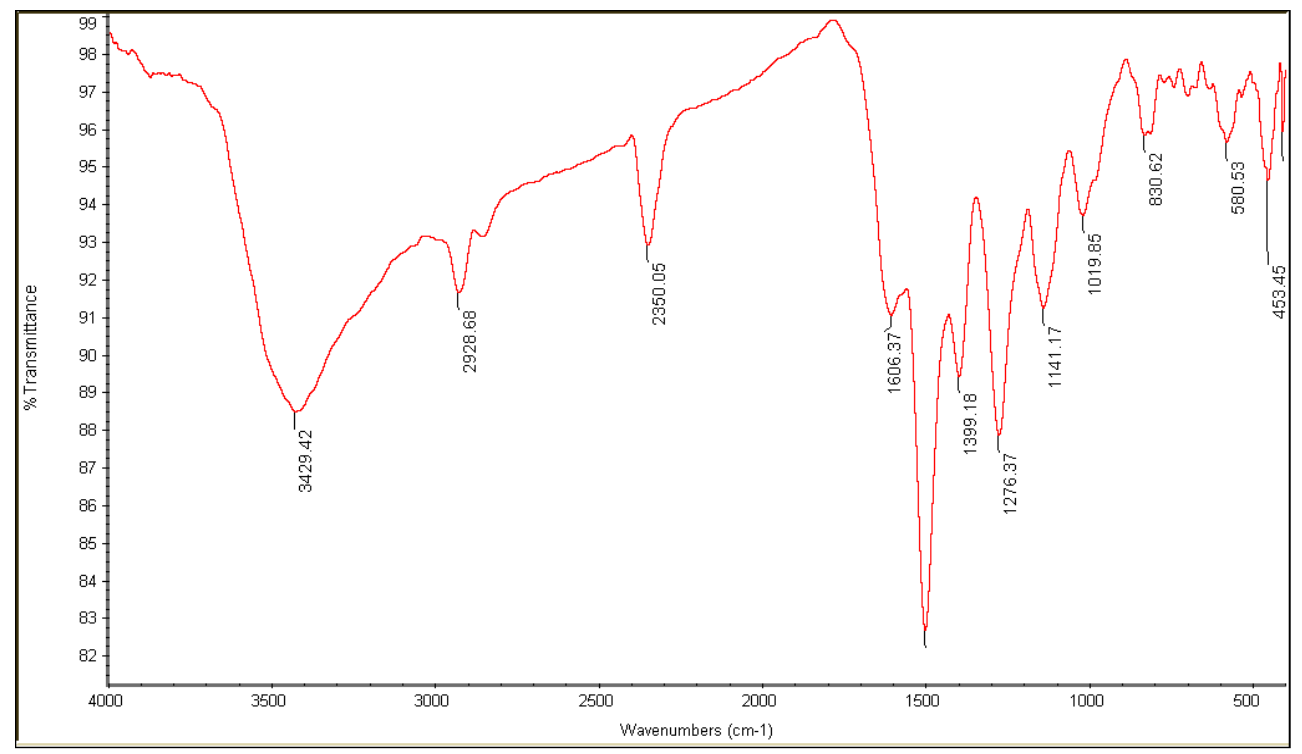

FTIR spectrum of $\mathrm{Cu}$-curcumin complex 


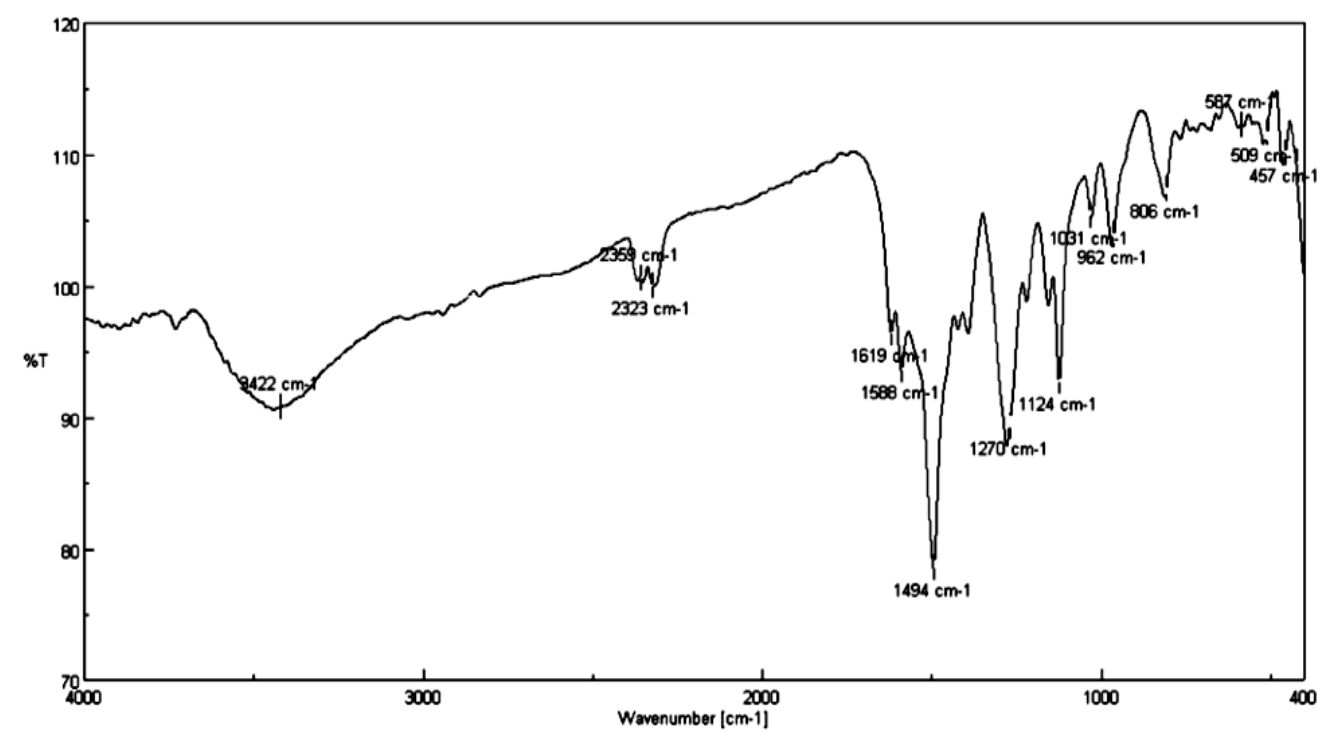

FTIR spectra of Ni-curcumin complex

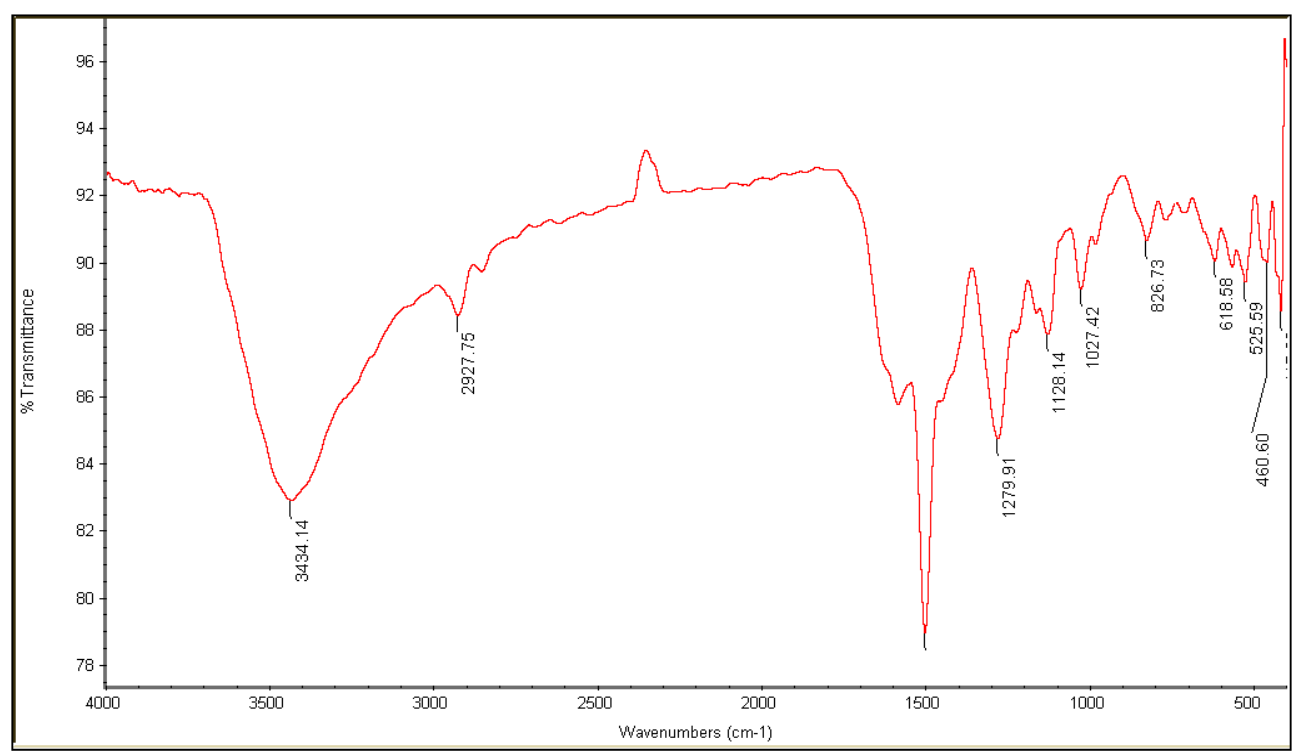

FTIR spectra of Co-curcumin complex

In 1:1 metal:enolate curcumin complex (Fig. 1), one of positive charge of metal is satisfied by the negative charge of the enolate ion. The conductance values of the complexes of curcumin-I in DMSO $\left(10^{-3} \mathrm{M}\right)$ are found to be $6,17,20,32$, and $20 \mathrm{ohm}^{-1} \mathrm{~cm}^{2} \mathrm{~mol}^{-1}$ for $\mathrm{Mn}$ (II), $\mathrm{Mg}$ (II), $\mathrm{Cu}(\mathrm{II}), \mathrm{Ni}(\mathrm{II})$ and $\mathrm{Co}(\mathrm{II})$ respectively which indicates non-electrolytic nature of the complexes. Hence it can be concluded that the chloride ions are being coordinated to the metal ion in the complexes. The thermal analysis data's of the complexes and ligand are provided as Supplementary material (S4) which shows the presence of coordinated water in the complexes. Curcumin was stable up to $150^{\circ} \mathrm{C}$ and the peak (DTG) observed at $160^{\circ}$ $\mathrm{C}$ can be attributed to the dehydroxylation of two $-\mathrm{OH}$ groups that is present in curcumin-I. After $400^{\circ} \mathrm{C}$ there is complete decomposition [28]. The Mn(II) complex showed a weight loss around $175^{\circ} \mathrm{C}$ due to loss of coordinated water (weight loss found: $3.7 \%$, calcd $3.8 \%$ ). The $\mathrm{Mg}$ (II) complex showed a weight loss up to $165^{\circ} \mathrm{C}$ due to loss of coordinated water (weight loss found: $3.8 \%$, calcd $4.0 \%$ ). Similarly Copper, Nickel and Cobalt complexes show a weight loss in the region $166^{\circ} \mathrm{C}, 162^{\circ} \mathrm{C}$ and $196^{\circ} \mathrm{C}$ due to loss of coordinated water with a weight loss of $4.0 \%, 3.5 \%$ and $3.6 \%$ against the calculated values of $3.7 \%, 3.6 \%$ and $3.8 \%$ respectively. The complexes showed a loss in weight in the region of $300^{\circ} \mathrm{C}$ corresponding to that of halogen. The TG/DTG and conductance measurement suggest a neutral coordination sphere.

S4 TG-DTG curves of (i) Curcumin-I, (ii) Mn-curcumin, (iii) Mg-curcumin, (iv) Cu-curcumin, (v) Ni-curcumin, (vi) Co-curcumin 


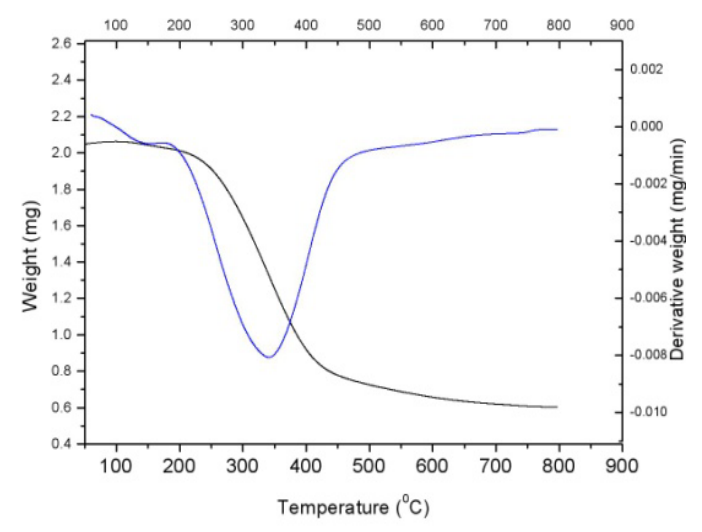

(i)

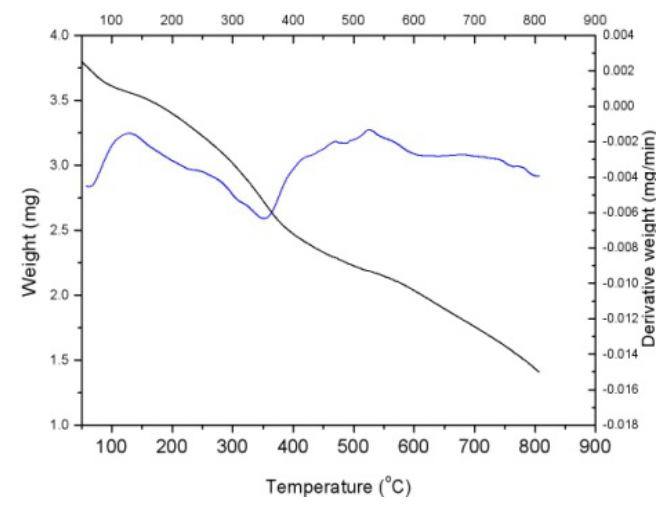

(ii)

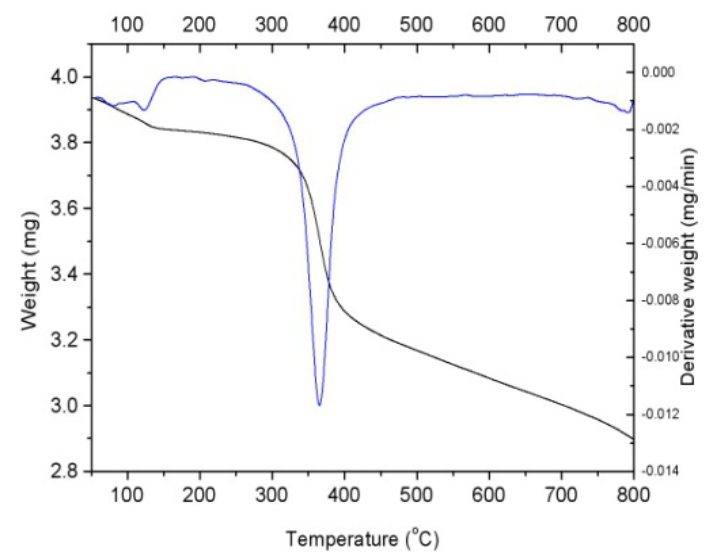

(iii)

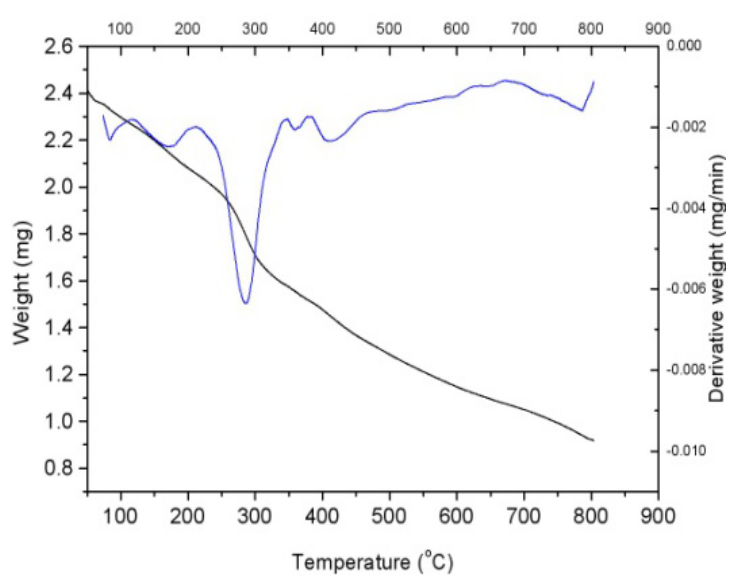

(iv)

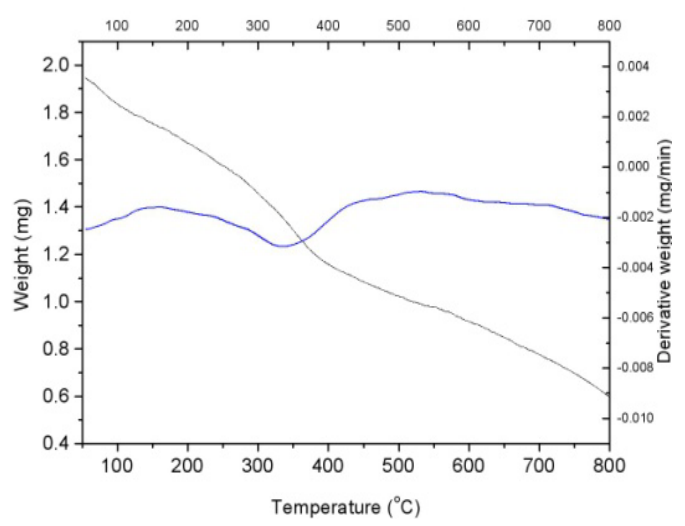

(v)

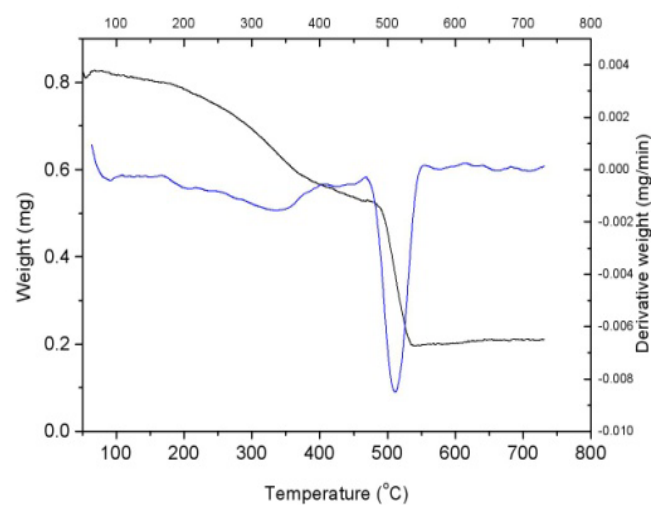

(vi)

The DPPH scavenging activity of metal complexes were less than that of curcumin-I (Fig 2)

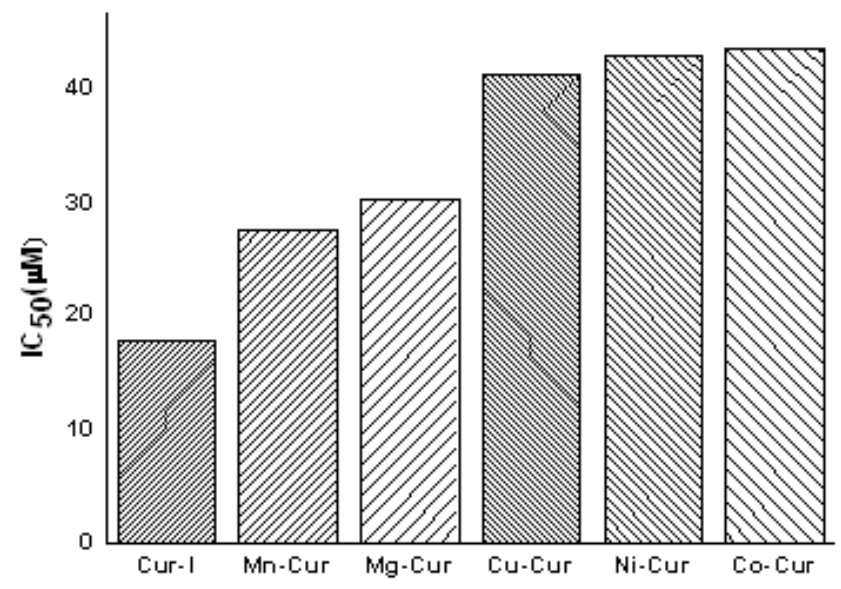

Figure 2. The comparison of $\mathrm{IC}_{50}(\mu \mathrm{M})$ of curcumin-I and its metal complexes

Table 1. $\mathrm{IC}_{50}(\mu \mathrm{M})$ of curcumin-I and its Metal complexes

\begin{tabular}{|c|c|}
\hline Materials & $\mathrm{IC}_{50}(\mu \mathrm{M})$ \\
\hline Curcumin & 17.88 \\
\hline Mn-Curcumin & 27.68 \\
\hline Mg-Curcumin & 30.28 \\
\hline Cu-Curcumin & 41.32 \\
\hline Ni-Curcumin & 42.92 \\
\hline Co-Curcumin & 43.56 \\
\hline
\end{tabular}




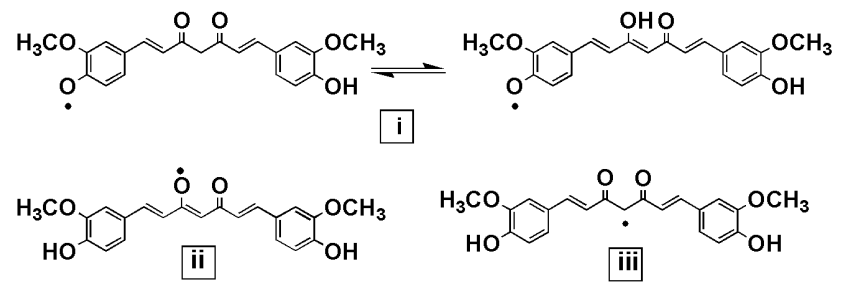

Figure 3. The free radical intermediates of curcumin

Scheme 2

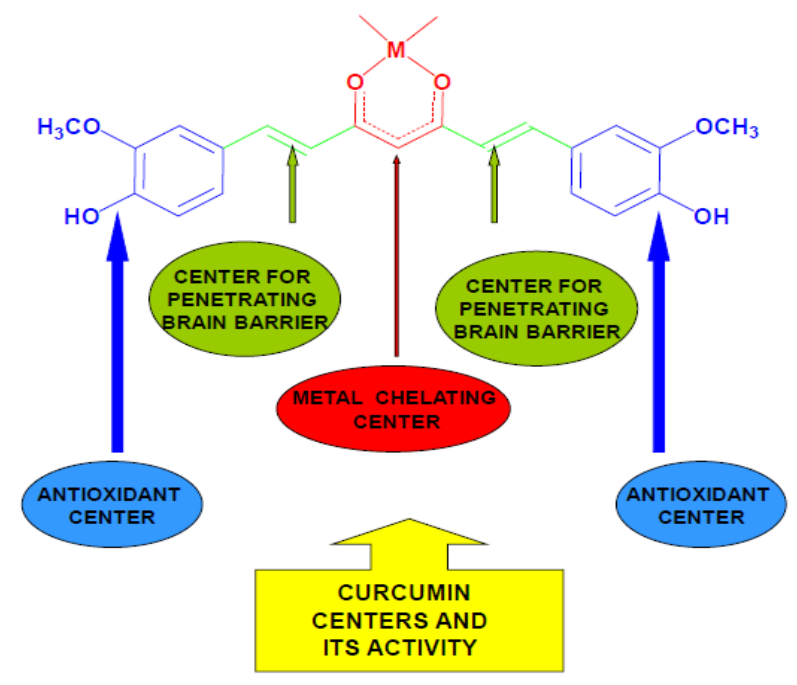

\section{Curcumin its reactive centers and activity}

The antioxidant activity of the complexes decreases in the order of $\mathrm{Mn}$ (II) $>\mathrm{Mg}$ (II) $>\mathrm{Cu}$ (II) $>\mathrm{Ni}$ (II) $>\mathrm{Co}$ (II) Table 1 . The difference in activity of curcumin-I and its complexes can be attributed to the involvement of different reaction centre of curcumin in free radical quenching. Different radical intermediate (Fig 3) were suggested by various group $[8,23,24,25]$ for explaining the antioxidant mechanism of curcumin.Accordingly hydrogen atom transfer (HAT) can take place from (i) phenolic-OH, (ii) enolic-OH, (iii) active methylene group $\left[-\mathrm{CH}_{2}\right]$ of diketo form of curcumin and the others by the resonance of phenoxide ion. In the metal complexes enol proton is unavailable, still appreciable free radical quenching is shown. This rejects the possible involvement of keto-enol moiety in antioxidant activity. Consequently contribution of reactive intermediates (ii and iii) in antioxidant mechanism can be neglected. Of all the reactive intermediate suggested, the only possible intermediate that could be generated in complexes is from phenolic-OH, which is expected to release hydrogen in polar protic solvent like methanol, by SPLET mechanism[29]. In the SPLET, a single electron transfer to DPPH takes place from $\mathrm{ArO}^{-}$. The changes in electronic effect at the diketo part of curcumin can influence the electron availability at $\mathrm{ArO}^{-}$ group there by the antioxidant activity. An electron donating group enhances the electron density at the $\mathrm{ArO}^{-}$group increasing the antioxidant activity. In curcumin, the enolate centre act as good electron donor, where as in the metal complexes the negative charge is transferred to metal (Fig.1) thereby, decreases the antioxidant activity. The present observation was in agreement with the Priyadarsini et al., 2003 [18], suggestion that the phenolic hydrogen is responsible for antioxidant activity and free radical kinetics of curcumin. Recently, our group reported antioxidant activity for Knoevenagel condensate of curcumin-I with benzaldehyde and salicylaldehyde [30] by the DPPH assay, harmonize the study with metal complexes. In the Knoevenagel condensate Supplementary material (S5), active methylene group of diketo form of curcumin condenses with aldehyde. The antioxidant activity of salicylaldehyde condensate was higher than the benzaldehyde condensate and the parent curcumin which was credited to the additional -OH group present. This proves that the keto-enol tautomerism is not a requisite for the radical quenching activity.

The biological activities of curcumin like anti-inflammatory, cholesterol-lowering, anti-Alzheimer are ascribed to its antioxidant property. In the present study it was shown that the metal complexes of curcumin have comparable antioxidant activity to curcumin and even after metal chelation it can act as antioxidant and hence expected to retain its other biological activity. Curcumin can act simultaneously as a metal chelator and antioxidant and in consequence an efficient brain protector. This property of binding of curcumin to metals and its utility as a multipotent agent for combating to oxidative stress and AD treatment have potential applications in its medication.

S5 Knoevenagel condensate - Preparation and Structure<smiles>[R]c1cc(/C=C/C(=O)C(=O)/C=C/c2ccc(O)c(OC)c2)ccc1/C=C/c1ccc(O)c(OC)c1</smiles>

(b) Salicylaldehyde $\left[\mathrm{R}_{1}-\mathrm{OH}\right] \quad$ Knoevenagel condensate 


\section{Conclusions}

In the complex of curcumin with $\mathrm{Mn}(\mathrm{II}), \mathrm{Mg}(\mathrm{II}), \mathrm{Cu}(\mathrm{II})$, $\mathrm{Ni}$ (II) and $\mathrm{Co}$ (II) the enolate form of curcumin ligands to the metal. The complexes have comparable antioxidant activity to parent curcumin-I. Equivalent antioxidant activity was established for Knoevenagel condensate of curcumin-I, with a diketo centre. All these fact ascertain the minimal involvement of keto-enol moiety of curcumin as the antioxidant centre and hold up the phenolic $-\mathrm{OH}$ as the prime centre for the antioxidant activity.

\section{REFERENCES}

[1] Majeed, M., Badmaev, V., Murrray, F., 1996. Turmeric and the Healing Curcuminoids. New Canaan. Connecticut: Keats Publishing, Inc.

[2] Chattopadhyay, I., Biswas, K., Bandyopdhyay, U., Banerjee, R.K., 2004. Turmeric and curcumin: Biological action and medicinal application. Curr. Sci. 87, 44-53.

[3] Wilken, R., Veena, M.S., Wang, M.B., Srivatsan, E.S., 2011. Curcumin: A review of anti-cancer properties and therapeutic activity in head and neck squamous cell carcinoma, Mole. Can. 10, 1-19.

[4] Surh, Y.J., 2002. Anti-tumor promoting potential of selected spice ingredients with antioxidative and anti-inflammatory activities: a short review. Food. Chem. Toxicol. 40, 1091-97.

[5] Anand, P., Thomas, S.G., Kunnumakkara A.B., Sundaram, C., Harikumar K.B., Sung B., Tharakan S.T., Misra, K., Priyadarsini, K. I., Rajasekharan, K.N., Aggarwal, B.B., 2008. Biological activities of curcumin and its analogues (Congeners) made by man and Mother Nature. Biochem. Pharm. 76, 1590-1611.

[6] Daniel, S., Lemon, J.L., Dairam, A., Watkins, G.M., Daya, S., 2004. Through metal binding, curcumin protects against lead and cadmium-induced lipid peroxidation in rat brain homogenates and against lead-induced tissue damage in rat brain. J. Inorg. Biochem. 98, 266-75.

[7] Cotton, F.A., Wilkinson, G., 1980. Advanced Inorganic Chemistry. John Wiley and sons, fourth ed. New York. 107-94.

[8] Barik, A., Mishra, B., Kunwar, A., Kadam, R.M., Shen, L., Dutta, S., Padhye, S., Satpati, A.K., Zhang, H.Y., Priyadarsini, K.I., 2007. Comparative study of copper (II)-curcumin complexes as superoxide dismutase mimics and free radical scavengers. Eur. J. Med. Chem. 42, 431-39.

[9] Borsari, M., Ferrari, E., Grandi, R., Saladini, M., 2002. Curcuminoids as potential new iron-agents: spectroscopic, polarographic and potentiometric study on their $\mathrm{Fe}$ (II) complexing ability. Inorg. Chim. Acta. 328, 61-68.

[10] Vajragupta, O., Boonchoong, P., Watanabe, H., Tohda, M., Kummasud, N., Sumanont, Y., 2003. Manganese complexes of curcumin and its derivatives: evaluation for the radical scavenging ability and neuroprotective activity. Free. Radic. Biol. Med. 35, 1632-44.
[11] Adlar, P.A., Bush, A.I., 2006. Metals and Alzheimer's disease. J. Alzheimers Dis. 10 145-63.

[12] Sreejayan., Rao, M.N.A., 1994. Curcuminoids as Potent Inhibitors of Lipid Peroxidation, J. Pharm. Pharmacol. 46, 1013-16.

[13] Balasubramanian, K., 2006. Molecular Orbital Basis for Yellow Curry Spice Curcumin's Prevention of Alzheimer's disease. J. Agric. Food. Chem. 54, 3512-20.

[14] Weggen, S., Eriksen, J.L., Das, P., Sagi, S.A., Wang, R., Pietrzik, C.U., Findlay, K.A., Smith, T.E., Murphy, M.P., Butler, T., Kang, D.E., Marquez-Sterling, N., Golde, T.E., Koo, E.H., 2001. A subset of NSAIDs lower amyloidogenic Abeta42 independently of cyclooxygenase activity. Nature. 414, 212-16.

[15] Yang, F., Lim, G.P., Begum, A.N., Ubeda, O.J., Simmons, M.R., Ambegaokar, S.S., Chen, P., Kayed, R., Glabe, C.G., Frautschy, S.A., Cole, G.M., 2005.Curcumin Inhibits Formation of Amyloid $\beta$ Oligomers and Fibrils, Binds Plaques and Reduces Amyloid in Vivo, J. Biol. Chem. 280, 5892-5901.

[16] Wright, J.S., 2002. Predicting the antioxidant activity of curcumin and curcuminoids, J. Mol. Struct. 591, 207-17.

[17] Sun, Y.M., Zhang, H.Y., Chen, D.Z., Liu, C.B., 2002. Theoretical elucidation on the antioxidant mechanism of curcumin: a DFT study. Org. Lett. 4, 2909-11.

[18] Priyadarsini, K.I., Maity, D.K., Naik, G.H., Kumar, M.S., Unnikrishnan, M.K., Satav, J.G., Mohan, H., 2003. Role of phenolic $\mathrm{O}-\mathrm{H}$ and methylene hydrogen on the free radical reactions and antioxidant activity of curcumin. Free. Radic. Biol. Med. 35, 475-84.

[19] Ligeret, H., Barthelemy, S., Zini, R., Tillement, J.P., Labidalle, S., Morin, D., 2004. Effects of curcumin and curcumin derivatives on mitochondrial permeability transition pore. Free. Radic. Biol. Med. 36, 919-29.

[20] Suzuki, M., Nakamura, T., Iyoki, S., Fujiwara, A., Watanabe, Y., Mohri, K., Isobe, K., Ono, K., Yano, S., 2005. Elucidation of anti-allergic activities of curcumin-related compounds with a special reference to their anti-oxidative activities. Biol. Pharm. Bull. 28, 1438-43.

[21] Chen, W.F., Deng, S.L., Zhou, B., Yang, L., Liu, Z.L., 2006. Curcumin and its analogues as potent inhibitors of low density lipoprotein oxidation: H-atom abstraction from the phenolic groups and possible involvement of the 4-hydroxy-3-methoxyphenyl groups. Free. Radic. Biol. Med. 40, 526-35.

[22] Barclay, L.R., Vinqvist, M.R., Mukai, K., Goto, H., Hashimoto, Y., Tokunaga, A., Uno, H., 2000. On the antioxidant mechanism of curcumin: classical methods are needed to determine antioxidant mechanism and activity. Org. Lett. 2, 2841-43.

[23] Venkatesan, P., Rao, M.N., 2000. Structure-activity relationships for the inhibition of lipid peroxidation and the scavenging of free radicals by synthetic symmetrical curcumin analogues, J. Pharm. Pharmacol. 52, 1123-28.

[24] Sugiyama, Y., Kawakishi, S., Osawa, T., 1996. Involvement of the beta-diketone moiety in the antioxidative mechanism of tetrahydrocurcumin. Biochem. Pharmacol. 52, 519-25. 
[25] Jovanovic, S.V., Steenken, S., Boone, C.W., Simic, M.G., 1999. H-atom transfer is a preferred antioxidant mechanism of curcumin. J. Am. Chem. Soc. 121, 9677-81.

[26] Somparn, P., Phisalaphong, C., Nakornchai, S., Unchern, S., Morales, N.P., 2007. Comparative Antioxidant Activities of Curcumin and Its Demethoxy and Hydrogenated Derivatives, Biol. Pharm. Bull. 30, 74-78.

[27] Annaraj, J.P., Ponvel, K.M., Athappan, P.R., 2004. Synthesis, spectra and redox behaviour of copper (II) complexes of curcumin diketimines as models for blue copper proteins. Transition. Met. Chem. 29, 722-27.
[28] Zebib, B., Mouloungui, Z., Noirot, V., 2010. Stabilization of Curcumin by Complexation with Divalent Cations in Glycerol/Water System, Bioinorg. Chem. Appl. 1-8.

[29] Litwinienko, G., Ingold, K.U., 2005. Abnormal Solvent Effects on Hydrogen Atom Abstraction. 3. Novel Kinetics in Sequential Proton Loss Electron Transfer Chemistry. J. Org. Chem.70, 8982-8990.

[30] Asha, R., Sudha, D.R., Sasikala, V., Priya, R.S., Balachandran, S., Mohanan, P.V., Annie, A., 2012. Bioactive Derivatives of Curcumin Attenuate Cataract Formation In Vitro. Chem. Biol. Drug. Des. 80, 887-92. 